\section{Mimics of Vasculitis: Vascular Ehlers-Danlos Syndrome Masquerading as Polyarteritis Nodosa}

\section{To the Editor:}

A 29-year-old African American man presented to the emergency department following a witnessed generalized seizure, his first. He provided a history of 3 days of abdominal discomfort prior to presentation, associated with constipation. History was remarkable for alprazolam abuse that he recently discontinued, and inguinal hernia repair as a child. There was no significant family history. Physical examination, laboratory studies, and computed tomography (CT) scan of the head were normal. A lumbar puncture was not performed. A second witnessed seizure prompted admission. Over the next 2 days he had no further neurological events but complained of persistent abdominal discomfort. On the third hospital day he developed a fever of $38.5^{\circ} \mathrm{C}$ associated with leukocytosis and decreasing hemoglobin, but normal chemistry results, amylase, and lipase. CT scan of the abdomen/pelvis revealed a ruptured splenic artery aneurysm with intraabdominal hemorrhage, splenic vein thrombosis, celiac artery aneurysm, bilateral external iliac artery aneurysms, renal artery aneurysm, and multiple splenic and renal infarcts. CT angiography further delineated the extent of the vascular abnormalities (Figure 1).
He was stabilized overnight, and transfused with packed red blood cells before going to surgery the following day. He underwent ligation of the splenic vessels, splenectomy, and partial pancreatectomy. His postoperative course was uncomplicated and he was discharged with routine followup.

Magnetic resonance imaging/angiography of the head and neck did not reveal a vascular cause for his seizures. CT of the chest did not reveal involvement of the thoracic aorta.

The autoantibody profile was negative. Pathologic examination showed no evidence of vasculitis and was initially believed to be most consistent with a diagnosis of segmental mediolytic arteriopathy (Figure 2). Molecular genetic testing revealed a mutation in the gene encoding the proa1(III) chain of type III collagen (COL3A1), diagnostic of vascular Ehlers-Danlos syndrome (vEDS), formerly known as Ehlers-Danlos syndrome type IV (EDS IV).

The first accounts of EDS described patients with joint and skin laxity, poor wound healing, and easy bruising ${ }^{1-4}$. Over time the classification of EDS grew until it included more than 10 types ascribed to different connective tissue abnormalities. Since 1997, the classification has been revised and simplified to 6 types based on clinical findings and biochemical and genetic testing, to include classical, hypermobility, vascular, kyphoscoliosis, arthrochalasia, and dermatosparaxis types ${ }^{5}$.

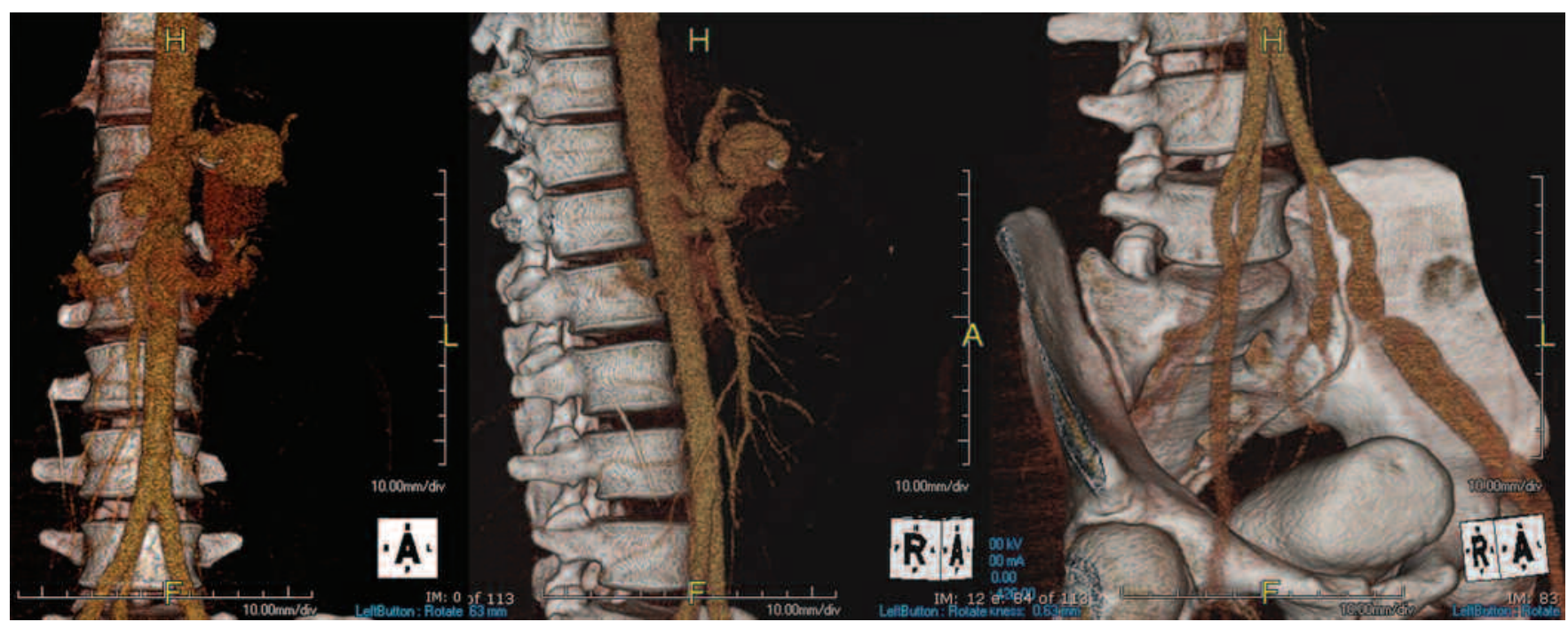

Figure 1. Sequence of reconstructed CT angiographic images showing aneurysms of the celiac artery and iliac arteries.

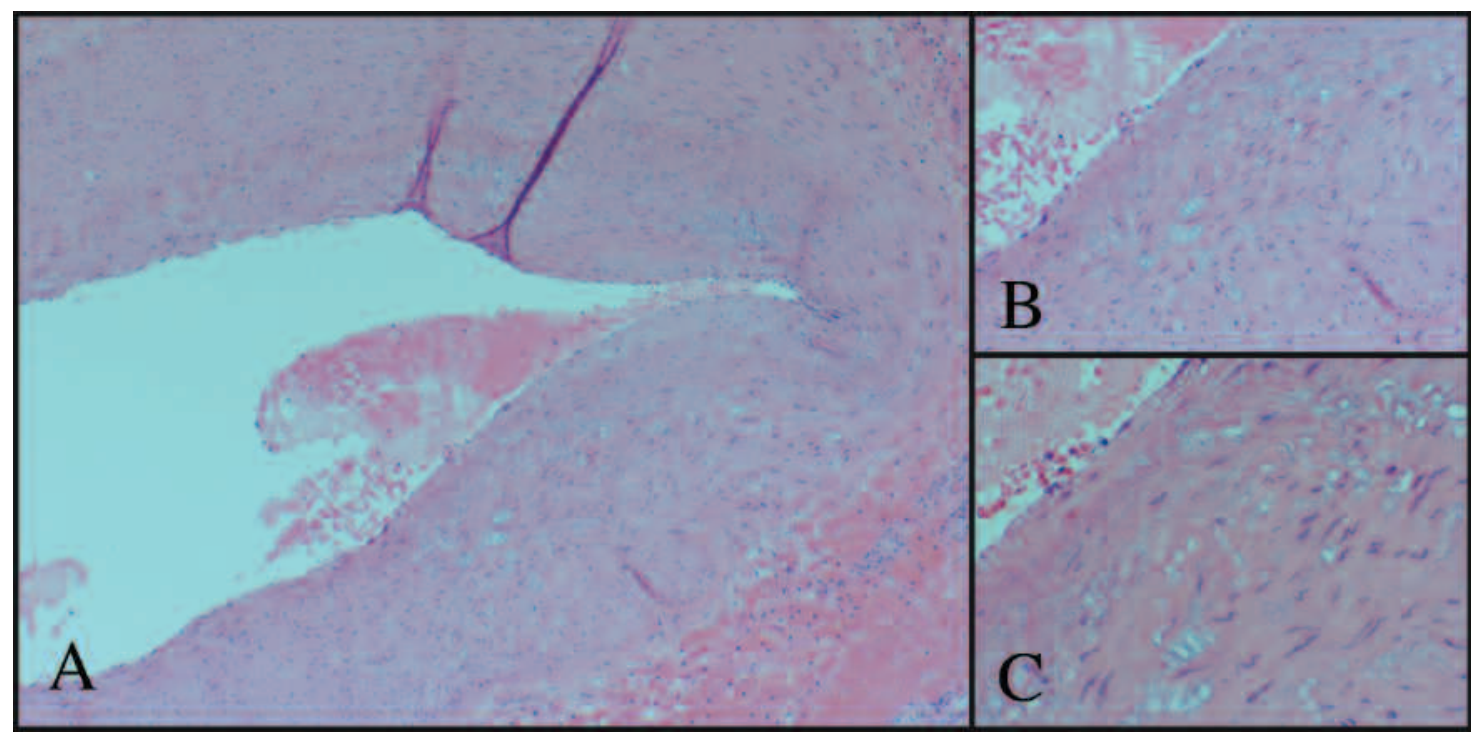

Figure 2. Microscopic histopathology specimens of the splenic artery showing dilation of the artery with deficient portions of the arterial wall and closely adherent extravasated blood and fibrin.

A. Magnification $\times 40$; B. $\times 100$; C. $\times 200$. 
vEDS is an autosomal-dominant connective tissue disorder, which earned its designation as the vascular type because it can present with catastrophic arterial, gastrointestinal, or uterine rupture ${ }^{6-9}$. Although joint and skin laxity is not common, patients often have easy bruising, thin skin with visible veins, or characteristic facial features (acrogeria). Diagnosis is confirmed by identification of mutations in the type III procollagen gene. The incidence is estimated at 4 per million. It exhibits complete penetrance, with no anticipation. In the largest cohort, the median age at death was 48 years, $20 \%$ had suffered a major complication by age 20 and $80 \%$ by age 40 years. Arterial rupture accounted for almost half of the major complications. The only congenital abnormalities associated with the cohort were a history of talipes equinovarus and congenital dislocation of the hip ${ }^{10}$.

Our patient did not have any outward sign of EDS, and there was no family history of sudden death or connective tissue disorders. His diagnosis was made only after his dramatic presentation ${ }^{10}$ and it is clear that there is a subgroup of such patients that are not diagnosed in time because their condition remains silent ${ }^{11}$. Unlike other cases in the literature, our patient's seizures were not related to his near-fatal splenic artery rupture ${ }^{11,12}$. The etiology of his seizures remains unclear, although they may have been related to benzodiazepine withdrawal or a subarachnoid hemorrhage not identified on CT. Since his original presentation, he has had only one sequelae: he presented 2 years after the initial event with headaches and a left fourth nerve palsy secondary to a left carotid cavernous fistula, which was treated endovascularly. Carotid cavernous fistulae are well described in the setting of vEDS ${ }^{13,14}$ and while intracranial hemorrhage from a fistula could provide a substrate for seizures, there was no evidence for intracranial hemorrhage at the index event. At his second presentation, the patient had a lumbar puncture positive for subarachnoid hemorrhage in the setting of a negative CT head scan.

While the immediate management of intraabdominal arterial rupture usually requires surgical or percutaneous intervention ${ }^{15,16}$, subsequent management of stable arterial aneurysms depends on the underlying etiology of the condition. This case highlights the diagnostic challenge in patients presenting with arterial rupture due to mimics of vasculitis ${ }^{17}$. A systemic vasculitis such as polyarteritis nodosa would warrant treatment with corticosteroids and other immunosuppressive drugs ${ }^{18}$. Treatment of vEDS with immunosuppressive therapy is unwarranted and may be harmful ${ }^{19}$. This case demonstrates that conditions such as segmental mediolytic arteriopathy that require histological diagnosis may be mistaken for other pathological entities, thus emphasizing the importance of molecular genetic testing in confirming the diagnosis.

RAMY A. BADAWI, MRCP, Cardiology Fellow, Department of Cardiology, Ochsner Clinic Foundation, New Orleans, Louisiana; LAWRENCE H. BRENT, MD, Head, Division of Rheumatology, Albert Einstein Medical Center, Philadelphia, Pennsylvania; DAVID E. FEINSTEIN, DO, Assistant Professor of Medicine, Cooper University Hospital, UMDNJ-Robert Wood Johnson Medical School, Camden, New Jersey, USA. Address correspondence to Dr. R.A. Badawi, Department of Cardiology, Ochsner Clinic Foundation, 1514 Jefferson Highway, New Orleans, LA 70121

E-mail: rbadawi@msn.com

\section{REFERENCES}

1. Van Meekeren JA. De dilatabilitate extraordinaria cutis. Observations Medico Chirugicales, Chapter 32. Amsterdam; 1682.
2. Chernogubow NA. Über einen Fall von Cutis laxa. Monatshefte für praktische Dermatologie, Hamburg, 1892;14:76.

3. Ehlers EL. Cutis laxa. Neigung zu Haemorrhagien in der Haut, Lockering mehrerer Artikulationen. Dermatologische Zeitschrift, Berlin, 1901;8:173-4.

4. Danlos H. Un cas de cutis laxa avec tumeurs par contusion chronique des coudes et des genoux (xanthome juvénile pseudo-diabetique de MM Hallopeau et Macé de Lépinay). Bulletin de la Societé francaise de dermatologie et de syphiligraphie, Paris, 1908;19:70-2.

5. Beighton P, De Paepe A, Steinmann B, Tsipouras P, Wenstrup R. Ehlers-Danlos syndromes: Revised nosology, Villefranche, 1997. Am J Med Genet 1998;77:31-7.

6. Sack G. Status dysvascularis, ein Fall von besonderer Zeereislichkeit der Blutgefässe. Deutsches Archiv für klinische Medicin, Leipzig, 1935-36;178:663-9.

7. Barabas AP. Heterogeneity of the Ehlers-Danlos syndrome: Description of three clinical types and a hypothesis to explain the basic defect(s). Br Med J 1967;2:612-3.

8. Barabas AP. Vascular complications in the Ehler-Danlos syndrome. J Cardiovasc Surg (Torino) 1972;13:160-7.

9. Pyeritz RE. Ehlers-Danlos syndrome. N Engl J Med 2000;342:730-2.

10. Pepin MG, Schwarze U, Superti-Furga A, Byers PH. Clinical and genetic features of Ehlers-Danlos syndrome type IV, the vascular type. N Engl J Med 2000;342:673-80.

11. Jarmulowicz M, Phillips WG. Vascular Ehlers Danlos syndrome undiagnosed during life. J Roy Soc Med 2001;94:28-30.

12. Sakata N, Takebayashi S, Shimizu K, et al. A case of segmental mediolytic arteriopathy involving both intracranial and intraabdominal arteries. Pathol Res Pract 2002;198:493-7.

13. Mitsuhashi T, Miyajima M, Saitoh R, Nakao Y, Hishii M, Arai H. Spontaneous carotid-cavernous fistula in a patient with Ehlers-Danlos syndrome type IV - case report. Neurol Med Chir (Toyko) 2004;44:548-53

14. Naesens R, Mestdagh C, Breemersch M, Defreyne L. Direct carotid-cavernous fistula: a case report and review of the literature. Bull Soc Belge Ophthalmol 2006;299:43-54.

15. Oderich GS, Panneton JM, Bower TC, et al. The spectrum, management and clinical outcome of Ehlers-Danlos syndrome type IV: a 30-year experience. J Vasc Surg 2005;42:98-106.

16. Ryan JM, Suhocki PV, Smith TP. Coil embolization of segmental arterial mediolysis of the hepatic artery. J Vasc Interv Radiol 2000;11:865-8.

17. Molloy ES, Langford CA. Vasculitis mimics. Curr Opin Rheumatol 2008;20:29-34.

18. Hagspiel KD, Angle JF, Spinosa DJ, Matsumoto AH. Polyarteritis nodosa systemic necrotizing vasculitis with involvement of hepatic and superior mesenteric arteries. Radiology 1999;212:359-64.

19. Chan RJ, Goodman TA, Aretz TH, Lie JT. Segmental mediolytic arteriopathy of the splenic and hepatic arteries mimicking systemic necrotizing vasculitis. Arthritis Rheum 1998;41:935-8.

J Rheumatol 2009;36:8; doi:10.3899/jrheum.081252 